\title{
Quantification of Epstein-Barr Virus and Human Cytomegalovirus in Chronic Periodontal Patients
}

\author{
Hengameh Khosropanah ${ }^{1}$; Maryam Karandish ${ }^{2, *}$; Mazyar Ziaeyan ${ }^{3}$; Marzieh Jamalidoust $^{3}$ \\ ${ }^{1}$ Periodontology Department, Dental School, Shiraz University of Medical Sciences, Shiraz, IR Iran \\ ${ }^{2}$ Orthodontic Department, Dental School, Shiraz University of Medical Sciences, Shiraz, IR Iran \\ 3 Professor Alborzi Clinical Microbiology Research Center, Namazi Hospital, Shiraz University of Medical Sciences, Shiraz, IR Iran \\ *Corresponding author:Maryam Karandish, Orthodontic Department, Dental School,Shiraz University of Medical Sciences, Shiraz, IR Iran. Tel:+98-9173376586, E-mail:karandishm@sums.ac.ir
}

Received: March 2, 2014; Revised: June 15, 2014; Accepted: November 18, 2014

\begin{abstract}
Background: Although studies focused mainly on the identification of periopathogenic bacteria, recent reports have suggested that various herpes viruses may also be involved in the occurrence and progression of different forms of periodontal diseases.

Objectives: This study aimed to compare the prevalence and load of Epstein-Barr Virus (EBV) and Human Cytomegalovirus (HCMV) in subgingival tissue specimens between chronic periodontitis and healthy sites.

Patients and Methods: A total of 60 samples from the systematically healthy patients with chronic periodontitis participated in this study (mean age, $35 \pm 7$ ). Clinical periodontal evaluation included the plaque index (PI) (Loe and Silness), bleeding on probing (BOP) (O'Leary), bleeding index, periodontal pocket depth (PPD) and clinical attachment level measurement. Tissue specimens harvested from $>6 \mathrm{~mm}$ periodontal pockets and from $\leq 3 \mathrm{~mm}$ sulcus depth in a quadrant of the same patient using periodontal curettes. Moreover, the unstimulated whole saliva was gathered as a shedding medium. A Taq-man Real-Time Polymerase Chain Reaction assay was used to identify genomic copies of periodontal HCMV and EBV. Data were analyzed by the Wilcoxon-signed ranks and Friedman tests using the SPSS 16 software.

Results: Out of 60 samples of subgingival tissues taken from the patients with chronic periodontitis, EBV count was the highest in saliva and the least in the tissue sample with $\mathrm{PD}<3 \mathrm{~mm}(\mathrm{P}<0.05)$. The highest HCMV count was in saliva and tissue samples with $\mathrm{PD}>6 \mathrm{~mm}(\mathrm{P}$ $<0.05)$.

Conclusions: According to the results of this study, quantification of HCMV and EBV observed in this study is high in periodontal tissue samples of severe chronic periodontitis.
\end{abstract}

Keywords: Periodontitis; Adult; Human Cytomegalovirus; Real-Time PCR

\section{Background}

Bacterial pathogens are causally necessary antecedents for the development of periodontitis but the more amount of bacterial plaque doesn't seem to provide a sufficient basis for explaining important clinicopathologic features of the disease. There is a dynamic interaction among various infections agents and interconnected cellular and humoral host response. Although studies focused mainly on the identification of periopathogenic bacteria, recent reports have suggested that various herpes viruses may also be involved in the occurrence and progression of different forms of periodontal disease (1-3). Herpes viruses can impact or alter structural cells and host defense cells of the periodontium and thereby reduce the ability of periodontal tissue to resist bacterial insult (4). Studies have shown the probable participation of Human Cytomegalovirus (HCMV) and Epstein-Barr Virus (EBV) in pathogenesis of the human periodontal disease (3). Recent reports showed that periodontium might constitute the site of infection or reservoir for human herpesviruses 6, and 7 (4). These viruses possess the biologic mechanism to modify the periodontal micro-environment and therefore might both favor the establishment of more pathogenic flora, and guide a pathogenic process $(3,5)$.

Data suggest increased frequency of specific members of the herpes viridae detection, such as EBV, HCMV and herpes simplex virus-1 (HSV-1) in various forms of periodontal diseases $(1,4,5)$. Contreras and Slots reported a higher HCMV amount in deep versus shallow periodontal pockets (6). He then showed a higher prevalence of HCMV, EBV-1 and HSV in Gingival Crevicular Fluid (GCF) of Acute Necrotizing Ulcerative Gingivitis (ANUG) suffering Nigerien children (7). Slots et al. postulated that the presence of HCMV and EBV-1 may interfere with reconstruc-

Copyright (C) 2015, Ahvaz Jundishapur University of Medical Sciences. This is an open-access article distributed under the terms of the Creative Commons Attribution-NonCommercial 4.0 International License (http://creativecommons.org/licenses/by-nc/4.0/) which permits copy and redistribute the material just in noncommercial usages, provided the original work is properly cited. 
tive periodontal treatment (8). Embracing HCMV with Dialister pneumosintes, a new periodontal disease pathogen and alveolar bone resorption has been reported (8). On the other hand, the presence of HSV and HCMV causes the presence of Porphyromonas gingivalis more predictable (9).

In another study, Mardirossian (4) reported that patients with periodontal disease were infected with HCMV and EBV, respectively. Jahangirnezhad (10) reported almost the same prevalence for HCMV and EBV-1 in subgingival plaque of aggressive periodontitis samples. Nibali et al. (11) could not detect HCMV, HSV and Varicella Zoster Virus (VZV) in chronic, generalized and localized aggressive periodontitis. They reported EBV detection in just 25\% of localized aggressive periodontitis and 10\% of healthy subgingival plaque specimens. In contrary in 2012 Das et al. evaluated the relationship between the presence of herpes viridae members and clinical parameters of the periodontal disease (12).

\section{Objectives}

We conducted the current study regarding to controversies on the relationship between the periodontal disease and herpes viridae in different populations. The purpose of this study was to quantify the presence of HCMV and EBV in chronic periodontitis patients with Real-Time PCR (RT-PCR) in a number of patients attended Shiraz Dental School.

\section{Patients and Methods}

The present study included 75 patients (age range, 23 . 64 years) who needed a periodontal pocket elimination surgery. Chronic periodontitis patients displayed clinical attachment loss of 6 - $9 \mathrm{~mm}$ and gingival inflammation in at least 3 posterior teeth. Inclusion criteria were as follows: The patients did not have any systemic condition such as: diabetes, heart disease, asthma. They claimed absence of herpetic infection history and didn't have any history of antibiotics within the previous 2 months. None of the patients had previous periodontal surgery. They all had at least 20 teeth. They did not report the history of smoking, pregnancy or lactation. The patient had at least one tooth with a $3 \mathrm{~mm}$ pocket depth in the flap extension region. The proposal was approved by committee of ethics, code: CT-85-3091, Shiraz University of Medical Sciences.

\subsection{Clinical Procedure}

Clinical periodontal evaluation included the plaque index (PI), bleeding on probing (BOP), bleeding index, periodontal pocket depth (PPD) and clinical attachment level measurement, from cemento enamel junction (CEJ) to the deepest probable pocket depth. We performed the measurements with Williams probe (Hu-Friedy, USA) in 6 parts: midfacial, midlingual, mesiofacial, mesiolingual, distofacial, distolingual aspects of each tooth. Patients had initially received a periodontal therapy consisting of oral hygiene instruction supragingival plaque and calculus removal by ultrasonic device at least 4 weeks before the periodontal surgery. The above-mentioned clinical assessments were repeated. We adopted patients with PD $>6 \mathrm{~mm}$ after the first phase of periodontal therapy. Immediately prior to the periodontal surgery, $1 \mathrm{~mL}$ unstimulated whole saliva was collected with the insulin syringe. Supragingival plaque and saliva were removed from selected quadrants with sterile cotton pellets and isolated with another cotton rolls.

The incision started with a Bard Parker blade N.15 and the epithelium of the pocket wall was removed. After raising the gingival flap, underlying connective tissue from the base of alveolar bone defect removed with a periodontal curette. Then the flap extended to reach the pocket depth of $>6 \mathrm{~mm}$. the connective tissue adjacent to this periodontal defect also was removed. The $1 \mathrm{~mm}$ tissue cuts were immediately immersed in a transport medium and delivered to the viral laboratory of Professor Alborzi Clinical Microbiology Center, Namazi Hospital, Shiraz University of Medical Sciences

\subsection{Laboratory Procedures}

The specimens were suspended in $600 \lambda$ of buffer (10 $\mathrm{mM}$ Trihydrochloride, $1 \mathrm{mM}$ EDTA with $\mathrm{pH}=8$ ) and homogenized by vigorous mixing on a vortex. The viral DNA extracted and precipitated using InviTrap $®$ Spin Blood RNA mini kit (Invitec- Berlin- Germany) as per the manufacturer's instructions; the viral DNA was eluted in $100 \mu \mathrm{L}$ of elusion buffer. The extracted samples quantified using commercially available viral kits (Genome Diagnostics Pvt. Ltd., Hague, Netherland). For each virus the final volume setup of $25 \mu \mathrm{L}$ Taq Man PCR (including $5 \mu \mathrm{L}$ of specimen, $12.5 \mu \mathrm{L}$ Mater Universal mixtures, 5 pmol primer, 4 pmol Taq Man probe) was adjusted. Limited PCR quantification was performed using plasmid dilution (one-copy per $\mathrm{mL}$ ). The evaluation process was as follows: $95^{\circ} \mathrm{C}$ for 10 minutes, followed by 50 cycles of $94^{\circ} \mathrm{C}$ for 10 seconds, $60^{\circ} \mathrm{C}$ for 32 seconds, and $72^{\circ} \mathrm{C}$ for 25 seconds. The reactions were performed in a 7500 RT- PCR system tool (Applied Biosystems, USA).

\section{Results}

Pairwise comparisons (between saliva specimen, tissue samples with $\mathrm{PD}<3 \mathrm{~mm}$ and tissue samples with PD $>6$ $\mathrm{mm}$ ) were checked using the Wilcoxon-signed rank test. Then the EBV and HCMV counts were compared with each other based on the Friedman test. If the differences were statistically significant, pairwise comparison was performed using the Wilcoxon-signed rank test.

The result on the comparison of each virus in saliva, PD $\leq 3 \mathrm{~mm}$ and $\mathrm{PD}>6 \mathrm{~mm}$ is demonstrated in the Table 1 and the results of the comparison between EBV and CMV counts in saliva and tissue samples are shown in Table 2. 
Khosropanah $\mathrm{H}$ et al.

\begin{tabular}{lcccc}
\hline \multicolumn{5}{l}{ Table 1. Comparison of Epstein-Barr Virus and Human Cytomegalovirus Counts Between Saliva and Tissue Samples ${ }^{\text {a }}$} \\
\hline Groups & Mean \pm SD & Median (Mean Rank) & Significant Pairwise Comparison & P Value $^{\mathrm{b}}$ \\
\hline EBV & & & & 0.00 \\
\hline Saliva & $4913.14 \pm 19260.73$ & $0.00(1.95)$ & $0.23^{\mathrm{C}}$ saliva vs. PD $>6 \mathrm{~mm}$ & \\
\hline PD $>6 \mathrm{~mm}$ & $3170.24 \pm 4877.76$ & $837.00(2.42)$ & $0.12^{\mathrm{C}}$ saliva vs. PD $\leq 3 \mathrm{~mm}$ & 0.013 \\
\hline PD $\leq 3 \mathrm{~mm}$ & $113.22 \pm 416.25$ & $0.00(1.64)$ & $0.00^{\mathrm{C}} \mathrm{PD}>6 \mathrm{~mm}$ vs. PD $\leq 3 \mathrm{~mm}$ & \\
\hline HCMV & & & $0.006^{\mathrm{C}}$ saliva vs. PD $\leq 3 \mathrm{~mm}$ & \\
\hline Saliva & $921.30 \pm 2158.63$ & $0.00(2.22)$ & $0.00^{\mathrm{C}} \mathrm{PD}>6 \mathrm{~mm}$ vs. PD $\leq 3 \mathrm{~mm}$ & \\
\hline PD $>6 \mathrm{~mm}$ & $623.27 \pm 1636.25$ & $0.00(1.99)$ & & \\
\hline PD $\leq 3 \mathrm{~mm}$ & $119.38 \pm 405.67$ & $0.00(1.80)$ & & \\
\hline
\end{tabular}

a Abbreviations: EBV, Epstein-Barr virus; HCMV, human cytomegalovirus.

b Based on Freidman test. P-values less than 0.05 are considered as statistically significant.

c Based on the Wilcoxon-signed-rank test.

Table 2. Comparison of Epstein-Barr Virus and Human Cytomegalovirus Counts in Saliva, pocket depth $>6$ mm and pocket depth $\leq$ $3 \mathrm{~mm}^{\mathrm{a}}$

\begin{tabular}{|c|c|c|c|}
\hline Groups & Mean $\pm S D$ & Median & PValue $^{b}$ \\
\hline Saliva & & & 0.009 \\
\hline EBV & $4913.14 \pm 19260.73$ & 0.00 & \\
\hline HCMV & $921.30 \pm 2158.63$ & 0.00 & \\
\hline $\mathrm{PD}>6 \mathrm{~mm}$ & & & 0.001 \\
\hline EBV & $3170.24 \pm 4877.76$ & 0.00 & \\
\hline HCMV & $623.27 \pm 1636.25$ & 0.00 & \\
\hline$P D \leq 3 \mathrm{~mm}$ & & & 0.917 \\
\hline EBV & $113.22 \pm 416.25$ & 0.00 & \\
\hline HCMV & $119.38 \pm 405.67$ & 0.00 & \\
\hline
\end{tabular}

a Abbreviations: EBV, Epstein-Barr virus; HCMV, human cytomegalovirus; and PD, pocket depth.

$\mathrm{b}$ Based on the Freidman test. P-values less than 0.05 are considered as statistically significant.

\subsection{Epstein-Barr Virus}

The EBV count in saliva was more than its amount in the tissue samples with PD $>6 \mathrm{~mm}$ and the EBV load in the tissue sample with PD $\leq 3 \mathrm{~mm}$ was the least (Table 1 ). All the differences were statistically significant $(\mathrm{P}<0.05)$.

\subsection{Human Cytomegalovirus}

The HCMV count in saliva was statistically equal to its count in the tissue with PD $>6 \mathrm{~mm}$. On the other hand, HCMV count was significantly lower in PD $\leq 3 \mathrm{~mm}$ tissue samples (Table 1).

\subsection{Human Cytomegalovirus and Epstein-Barr Vi- rus Comparison}

In comparison of HCMV and EBV counts, the EBV load was statistically higher in the tissue samples with PD $>6$ $\mathrm{mm}(\mathrm{P}=0.001)$. In comparison of HCMV and EBV counts in saliva, the differences were not statistically significant (P > 0.05). In comparison of HCMV and EBV counts, the difference in tissue samples with $\mathrm{PD}<3 \mathrm{~mm}$ was not sta- tistically significant $(\mathrm{P}>0.05)$. On the other hand, EBV count was significantly higher than HCMV in tissue samples with $\mathrm{PD}>6 \mathrm{~mm}(\mathrm{P}<0.05)$ (Table 2$)$. The frequency of HCMV was $35.1 \%$ in saliva, $21.6 \%$ in PD $>6 \mathrm{~mm}$ and $10.8 \%$ in $\mathrm{PD} \leq 3 \mathrm{~mm}$. The frequency of EBV in the same group was $21.6 \%$ in saliva, $51.3 \%$ in $\mathrm{PD}>6 \mathrm{~mm}$ and $8.1 \%$ in $\mathrm{PD} \leq 3 \mathrm{~mm}$.

\section{Discussion}

The current study was designed to evaluate HCMV and EBV in periodontal tissues of chronic periodontitis patients using the RT-PCR. We observed the highest amount of HCMV in saliva and PD $>6 \mathrm{~mm}$ tissue specimens and the highest amount of EBV in PD $>6 \mathrm{~mm}$ tissue specimens of patients with chronic periodontitis. Recent studies have demonstrated the association between herpes viridae and the periodontal disease. Different herpes viruses (e.g. EBV, HCMV, HSV and human herpes virus (HHV 6-8) and Transfusion Transmitted Virus (TTV) have been introduced to accompanying with the periodontal disease $(10,13,14)$. In addition to cytopathic and immunopathic harmful effects of herpes viridae, the ability of latency 
and reactivation of these viruses can affect the propagation of periodontitis (4). Such effect may be resulted from septic and immunopathic cascades, which can cause destructive cytokine release (8). Another study also insisted that concomitant occurrence of these viruses may have more negative effect on periodontal wellbeing (10).

They reported that EBV and HSV-1 are related to chronic and aggressive periodontitis. They added that probing depth and attachment loss were higher in the presence of these viruses (12). According to previous studies, higher frequencies of virus in GCF were reported in periodontal disease sites in comparison with gingivitis and healthy sites $(6,14-17)$. Another group of studies evaluated the frequency of viral presence in subgingival plaque. In these studies detection of high frequency of viral load was reported in the periodontal disease in comparison with healthy sites $(6,10,13,15,18-21)$. Our study confirmed these results considering EBV and HCMV counts. On the other hand, Contreras et al. could not detect any HCMV and EBV particles in healthy periodontal tissue (1) which is in contrast with our results. The same authors in 2000 postulated the presence of these viruses both in healthy and periodontally disease sites. In our study, we observed the highest EBV count in tissue sample with PD $>6 \mathrm{~mm}$ and the lowest in saliva. The cytomegalovirus count was in its highest number in tissue samples with PD $>6 \mathrm{~mm}$ too.

Variable amounts of viral prevalence have been reported in different populations. Although Saygun in 2002 showed HCMV in $44 \%$ of chronic periodontitis patients (19), this virus was detected in $14 \%$ of healthy Turkish samples and $17 \%$ and $7 \%$ for EBV and HSV, respectively. Imbronito (18) and Bilichodmath (13) reported that HSV-1 and EBV-1 were more frequently associated with chronic periodontitis and aggressive periodontitis, respectively. Since the percentages varied greatly [for EBV: 78.9\% (13), 46.7\%, for HSV-1: 100\% (13), 40\% (18) and for HCMV: $26.31 \%$ (13), 50\% (18)], the results were not completely similar to the current study. This can be related to the design of these studies; both of them before those studies $(13,18)$ detected viruses in subgingival plaque samples, not tissue samples. We observed EBV and HCMV in both PD $\leq 3$ $\mathrm{mm}$ and $\mathrm{PD}>6 \mathrm{~mm}$ tissue samples.

Most of the studies evaluated viral infection using the $\operatorname{PCR}(10)$ or nested PCR $(13,14,18,22)$; however, in the present study we adopted RT-PCR. Polymerase chain reaction is a gene amplification method, which allows very small microorganism quantities detection with selective DNA segment manipulation (23). Although nested PCR is sometimes adopted for its specificity and sensitivity, it can produce false positive results due to its contamination susceptibility technique (23). Real-time PCR is a more appropriate quantitative method for detection of viruses. Polymerase chain reaction is a qualitative test that just focuses on the existence of virus, which can be affected by confounding environmental factors. In addition, EBV and HCMV can remain latent in lymphocytes which are the normal inhabitants of periodontal sulcus and pocket wall; so, mere existence of viruses is not valuable enough. HCMV infection has direct and indirect (TNF- $\alpha$, IL-1 $\beta$ secretion) pathogenic effects on periodontal fibroblasts and epithelial cells (24). We collected the whole saliva to prevent the probable adverse effect of insufficient GCF volume.

Some studies such as Saygun et al. did not compare their test group with a normal control group; however, we adopted tissue samples with $\mathrm{PD}<3 \mathrm{~mm}$ and $\mathrm{PD}>6$ $\mathrm{mm}$ (17). Yildirim et al. reported HCMV and EBV detection in Kostmann syndrome with RT- PCR in 2006 (25). On the other hand, Saygun et al. classified chronic and aggressive periodontitis just by age range, which does not seem to be scientific (17). Due to their study, EBV DNA was identified in more samples than HCMV DNA, which is in agreement with the results of our study. They proposed a positive correction for EBV gingival tissue counts and gingival index. They concluded that the elevated amount of HCMV and EBV in periodontal pocket and gingival tissue was seen in aggressive periodontitis compared with chronic periodontitis.

We observed 13.5\% HCMV and EBV-1 coinfection in saliva and tissue samples with PD $\leq 3 \mathrm{~mm}$ and $\mathrm{PD}>6 \mathrm{~mm}$. This result was in line with Jahangirnezhad (10) and Kubar et al. (21) studies that reported 52\% HCMV and EBV-1 coinfection in aggressive periodontitis respectively. Kubar et al. also reported a $27 \%$ confection in chronic periodontitis (26). Grenier et al. (14) showed higher copy number of HCMV presence in GCF of deep periodontal pockets which is in agreement with our study on tissue samples. They also postulated that periodontal therapy can eliminate EBV and HCMV, and reduce HSV in GCF. In current study, saliva performed as a shedding site for viruses. The higher number of EBV viruses in deep pockets in comparison with saliva, can attribute them as a reservoir of this virus. On the other hand, the HCMV count was higher in saliva compared with tissue samples. This can be related to the probable elimination of the epithelial pocket wall during surgical procedure.

Some difficulties of virus DNA extraction from tissue samples are as follows: 1) It is hard to extract specimen from unattached flappy tissue, 2) Small and variable size of tissue samples, and 3) The probability of contamination of the specimen during manipulation. We suggest a cohort study for an investigation on the cause and effect relationship of the herpes viruses in the periodontal disease.

Current cross-sectional study demonstrated considerable number of viruses present in this sample population. However, EBV and HCMV may play an effective role on the severity of the periodontal disease and their control can pave the way for better periodontal treatment.

\section{Acknowledgements}

The authors would like to thank the research vice-chan- 
cellor of Shiraz University of Medical Sciences and Professor Alborzi Clinical Microbiology Research Center for their financial and material support, respectively.

\section{Authors' Contributions}

Maryam Karandish suggested the subject of the study with the scientific supervision of Hengameh Khosropanah. Maryam Karandish, Hengameh Khosropanah and Mazyar Ziaeyan participated in the design of the study. Hengameh Khosropanah and Maryam Karandish helped with the periodontal surgery. Maryam Karandish and Marzieh Jamalidoust carried out the laboratory procedures. Maryam Karandish performed the statistical analysis and prepared the draft of the manuscript. Hengameh Khosropanah, Mazyar Ziaeyan and Marzieh Jamalidoust edited the draft and finally all the authors approved the final manuscript.

\section{References}

1. Contreras A, Umeda M, Chen C, Bakker I, Morrison JL, Slots J. Relationship between herpesviruses and adult periodontitis and periodontopathic bacteria. J Periodontol.1999;70(5):478-84.

2. Contreras A, Slots J. Herpesviruses in human periodontal disease. J Periodontal Res. 2000;35(1):3-16.

3. Contreras A, Nowzari H, Slots J. Herpesviruses in periodontal pocket and gingival tissue specimens. Oral Microbiol Immunol. 2000;15(1):15-8.

4. Mardirossian A, Contreras A, Navazesh M, Nowzari H, Slots J. Herpesviruses 6, 7 and 8 in HIV- and non-HIV-associated periodontitis. J Periodontal Res. 2000;35(5):278-84.

5. Slots J, Contreras A. Herpesviruses: a unifying causative factor in periodontitis? Oral Microbiol Immunol. 2000;15(5):277-80.

6. Contreras A, Slots J. Mammalian viruses in human periodontitis. Oral Microbiol Immunol. 1996;11(6):381-6.

7. Contreras A, Falkler WJ, Enwonwu CO, Idigbe EO, Savage KO, Afolabi $\mathrm{MB}$, et al. Human Herpesviridae in acute necrotizing ulcerative gingivitis in children in Nigeria. Oral Microbiol Immunol. 1997;12(5):259-65.

8. Slots J, Sugar C, Kamma JJ. Cytomegalovirus periodontal presence is associated with subgingival Dialister pneumosintes and alveolar bone loss. Oral Microbiol Immunol. 2002;17(6):369-74.

9. Slots J, Kamma JJ, Sugar C. The herpesvirus-Porphyromonas gingivalis-periodontitis axis. J Periodontal Res. 2003;38(3):318-23.

10. Jahangirnezhad M. Subgingival Human Cytomegalovirus and Epstein Barr Virus in Patients with Aggressive Periodontitis in Ahwaz, Iran.J Dent. 2009;6(2):63-6.

11. Nibali L, Atkinson C, Griffiths P, Darbar U, Rakmanee T, Suvan J, et al. Low prevalence of subgingival viruses in periodontitis patients. J Clin Periodontol. 2009;36(11):928-32.

12. Das S, Krithiga GS, Gopalakrishnan S. Detection of human herpes viruses in patients with chronic and aggressive periodontitis and relationship between viruses and clinical parameters. J Oral Maxillofac Pathol. 2012;16(2):203-9.

13. Bilichodmath S, Mangalekar SB, Sharma DC, Prabhakar AK, Reddy SB, Kalburgi NB, et al. Herpesviruses in chronic and aggressive periodontitis patients in an Indian population. J Oral Sci. 2009;51(1):79-86.

14. Grenier G, Gagnon G, Grenier D. Detection of herpetic viruses in gingival crevicular fluid of patients suffering from periodontal diseases: prevalence and effect of treatment. Oral Microbiol Immunol. 2009;24(6):506-9.

15. Parra B, Slots J. Detection of human viruses in periodontal pockets using polymerase chain reaction. Oral Microbiol Immunol. 1996;11(5):289-93.

16. Contreras A, Slots J. Active cytomegalovirus infection in human periodontitis. Oral Microbiol Immunol.1998;13(4):225-30.

17. Saygun I, Kubar A, Ozdemir A, Slots J. Periodontitis lesions are a source of salivary cytomegalovirus and Epstein-Barr virus.J Periodontal Res. 2005;40(2):187-91.

18. Imbronito AV, Okuda OS, Maria de Freitas N, Moreira Lotufo RF, Nunes FD. Detection of herpesviruses and periodontal pathogens in subgingival plaque of patients with chronic periodontitis, generalized aggressive periodontitis, or gingivitis. J Periodontol. 2008;79(12):2313-21.

19. Saygun I, Sahin S, Ozdemir A, Kurtis B, Yapar M, Kubar A, et al. Detection of human viruses in patients with chronic periodontitis and the relationship between viruses and clinical parameters. $J$ Periodontol. 2002;73(12):1437-43.

20. Yapar M, Saygun I, Ozdemir A, Kubar A, Sahin S. Prevalence of human herpesviruses in patients with aggressive periodontitis. $J$ Periodontol. 2003;74(11):1634-40.

21. Kubar A, Saygun I, Yapar M, Ozdemir A, Slots J. Real-time PCR quantification of cytomegalovirus in aggressive periodontitis lesions using TaqMan technology. J Periodontal Res. 2004;39(2):81-6.

22. Contreras A, Zadeh HH, Nowzari H, Slots J. Herpesvirus infection of inflammatory cells in human periodontitis. Oral Microbiol Immunol.1999;14(4):206-12.

23. Burkardt HJ. Standardization and quality control of PCR analyses. Clin Chem Lab Med. 2000;38(2):87-91.

24. Idesawa M, Sugano N, Ikeda K, Oshikawa M, Takane M, Seki K, et al. Detection of Epstein-Barr virus in saliva by real-time PCR. Oral Microbiol Immunol. 2004;19(4):230-2.

25. Yildirim S, Yapar M, Kubar A, Slots J. Human cytomegalovirus, Epstein-Barr virus and bone resorption-inducing cytokines in periapical lesions of deciduous teeth. Oral Microbiol Immunol. 2006;21(2):107-11.

26. Kubar A, Saygun I, Ozdemir A, Yapar M, Slots J. Real-time polymerase chain reaction quantification of human cytomegalovirus and Epstein-Barr virus in periodontal pockets and the adjacent gingiva of periodontitis lesions. J Periodontal Res. 2005;40(2):97-104. 